\title{
Time spent lying, sitting, and upright during hospitalization after stroke: a prospective observation study
}

\author{
Ole Petter Norvang ${ }^{1,2^{*}}$ D, Anne Hokstad ${ }^{1,3}$, Kristin Taraldsen ${ }^{1}$, Xiangchun Tan ${ }^{1}$, Stian Lydersen ${ }^{4}$, Bent Indredavik ${ }^{1,3}$
} and Torunn Askim ${ }^{1,3}$

\begin{abstract}
Background: Early mobilization has been an important part of acute stroke unit treatment. However, early and intense mobilization within the first $24 \mathrm{~h}$ post stroke may cause an unfavorable outcome. Recently, objective measurements using body-worn sensors have been applied, enabling continuous monitoring of physical activity in the hospital setting. This study aimed to use body-worn sensors to quantify the amount of physical activity and how activity levels changed over time during hospitalization in patients with acute stroke. We also wanted to investigate which factors were associated with upright and sitting activity.

Methods: This was a prospective study including patients admitted to hospital within seven days after onset of stroke. Physical activity was measured by two sensors (ActivPALs from PAL Technologies Ltd., Glasgow, UK), one attached on sternum and one on the thigh of the unaffected side, monitoring continuously from inclusion until discharge. Data were processed in Matlab R 2015B and provided information about daily time in lying, sitting, and upright positions, and daily average duration of sitting and upright bouts. A linear mixed model was used to analyze changes over time.
\end{abstract}

Results: 58 patients were included (31 women, mean (SD) age; 75.1 (12.0)). Patients were hospitalized for 12.1 (7.6) days and had a mean score on the National Institute of Health Stroke Scale of 6.2 (5.5) points. Time spent sitting and time spent upright increased per day during hospitalization by $22.10 \mathrm{~min}$ (95\% Confidence interval (Cl): 14.96, $29.24)$ and 3.75 min $(95 \%$ Cl: $1.70,5.80)$ respectively. Increased time upright was associated with improved Modified Rankin Scale scores $(-38.09$ min, 95\% Cl: $-61.88,-14.29)$ and higher Short Physical Performance Battery scores (6.97 min, 95\% Cl: 1.99, 11.95), while prolonged bouts of sitting were associated with more severe stroke (4.50 min, $95 \% \mathrm{Cl}: 0.80,8.19)$, and older age (1.72 min, 95\% Cl: 0.20, 3.26).

Conclusions: Patients increased their daily time spent sitting and upright during the initial hospital stay after stroke. Prolonged bouts of sitting were associated with older age and more severe strokes. Hence future research should investigate the benefit of interventions aimed at breaking up sitting time after stroke.

Keywords: Stroke, Early rehabilitation, Accelerometer, Physical activity

\footnotetext{
* Correspondence: olepn@ntnu.no

${ }^{1}$ Department of Neuromedicine and Movement Science, Faculty of Medicine

and health science, NTNU - Norwegian University of Science and

Technology, Trondheim, Norway

${ }^{2}$ Clinical Services, Department of Physiotherapy, St Olavs Hospital, Trondheim

University Hospital, NO-7006 Trondheim, Norway

Full list of author information is available at the end of the article
}

(c) The Author(s). 2018 Open Access This article is distributed under the terms of the Creative Commons Attribution 4.0 International License (http://creativecommons.org/licenses/by/4.0/), which permits unrestricted use, distribution, and reproduction in any medium, provided you give appropriate credit to the original author(s) and the source, provide a link to the Creative Commons license, and indicate if changes were made. The Creative Commons Public Domain Dedication waiver (http://creativecommons.org/publicdomain/zero/1.0/) applies to the data made available in this article, unless otherwise stated. 


\section{Background}

One of the core elements of care for dedicated comprehensive stroke units is acute medical treatment combined with early rehabilitation [1-3]. Early rehabilitation with mobilization out of bed during hospitalization has shown to be associated with better functional outcomes for patients after stroke [4-8]. This may reduce the loss of muscle mass, increase muscle strength $[6,9]$, avoid complications $[3,4,10]$, exploit the plasticity of the brain [11], improve neurological functioning [12], and improve gait function [13]. Although time spent out of bed early after stroke varies significantly between hospitals [14-16], the amount of physical activity is generally low during hospital stays $[17,18]$.

Optimal timing and intensity of early mobilization is, however, not clear, as previous studies have shown an association between mobilization within the first $24 \mathrm{~h}$ and a negative trend towards increased dependency $[12,19]$ and increased mortality [20]. On the other hand, short and frequent mobilizations have been associated with improved outcome [21].

Most studies of physical activity during hospitalization have been single-day observational studies during daytime hours. Recently, objective measurements using body-worn single sensor activity monitors have been applied, enabling continuous monitoring of physical activity over time [22, 23]. So far, only a few studies have used activity monitors to distinguish between different activities in the acute phase for stroke patients [24]. In one of these studies, Strømmen et al. (2014) found significantly increased activity in the lower extremities for hospitalized stroke patients from the first day until discharge [25]. The increased activity was significantly associated with lower severity of stroke, whereas decreased activity was found with increasing age [25]. However, the study did not discriminate between times spent in different positions, which is crucial when measuring physical activity in the acute phase after stroke. Applying two single sensors from the ActivPAL sensor system, one on the chest and one on the thigh, makes it possible to quantify the amount of time spent in different positions. This method has previously been proved valid for stroke patients [26].

The main aim of this study was to describe the amount of time spent in lying, sitting and upright (standing or walking) positions early after stroke and how these activity levels changed during the hospital stay, both regarding total time per day and duration for each mobilization. Another aim was to examine which factors were associated with total time and bouts of sitting and upright activity. Our primary hypothesis was that patients would gradually increase time spent in an upright position, and thereby increase the duration of each upright bout.

\section{Method}

\section{Design}

This study used a prospective observation design, measuring physical activity continuously with two activity monitors for three to seven consecutive days during hospitalization.

\section{Study setting}

All patients were treated in an evidence-based comprehensive stroke unit that emphasizes a multidisciplinary approach and early rehabilitation. The treatment focused on independence in daily life. All patients, regardless of participation, received routine medical treatment, including rehabilitation, in accordance with Norwegian guidelines for treatment and rehabilitation after stroke [27].

\section{Study population}

Patients were recruited during three time periods, OctoberDecember 2013, May-December 2014, and March-August 2016. Patients admitted to Trondheim University Hospital, Norway, with diagnosed first ever or recurrent acute ischemic or hemorrhagic stroke were eligible for inclusion if the onset of stroke had been within seven days, they spoke fluent Norwegian, and if they gave written consent. In line with the Norwegian regulations for informed consent, patients who were unable to consent were included if their next of kin not opposed participation. Patients with terminal illness, other health conditions severely affecting their ability to walk, or expected discharge within three days after inclusion were excluded.

\section{Measurements}

The ActivPAL Professional sensor system (from PAL Technologies Ltd) consists of a three-axis accelerometer that collects continuous data with a sampling frequency of $10 \mathrm{~Hz}$, and with a battery capacity of up to 14 days. The primary outcome for this study was whether time spent lying, sitting or upright changed during the hospital stay. It has previously been shown that this activity monitor provides valid data for time spent lying, sitting, standing and walking $[28,29]$ and that placement on the thigh and sternum provides good validity for postures and transitions compared to video observations [26]. The 24-h period was measured from the time the activity monitors were attached. Duration of sitting bouts was estimated according to the following ratio: time spent in sitting/ number of transitions from lying to sitting, while duration of upright bouts was estimated correspondingly. A time threshold for transitions was set at $1.5 \mathrm{~s}$ to eliminate unreliable event records.

The Short Physical Performance Battery (SPPB) (ranging from 0 to 12 , where 12 is the best score) was used to assess physical function. The test consists of three different mobility tasks, and has been found to be both valid and 
reliable for assessing physical function amongst elderly people [30]. Gait speed was calculated based on the walking task of the SPPB. An experienced nurse or physiotherapist performed the test.

Global function was defined using the Modified Rankin Scale (mRS) (ranging from 0 to 6 , where 0 is normal function and 6 denotes death) [31] at admission and after the first day in hospital. The mRS measures independence in activities of daily living.

The National Institutes of Health Stroke Scale (NIHSS) was used to measure severity of the stroke. The scale is widely used and has proved both valid and reliable [32].

Both mRS and NIHSS were scored by an experienced clinician within the first day after the patient's admission and recorded together with age, gender, number of days from first symptom to admission date, and number of days at the hospital, which were collected from the medical record.

\section{Procedure}

All patients accepting participation had two ActivPAL activity monitors attached, one at the sternum and one at the unaffected thigh, to distinguish between lying, sitting and upright position. If neither of the lower extremities were affected by the stroke, the activity monitor was attached to the right thigh. Patients were instructed to follow the standard rehabilitation routines without paying attention to the equipment. Both activity monitors were removed 14 days post stroke unless the patient had been discharged earlier. Data from the activity monitors were transferred via a USB docking station, and processed in Matlab R2015 B. The valid body and leg data had an individual start and stop time defined and used to measure a count for a full 24-h day, and the activity was coded in reference to the body position. To distinguish the different positions, data from the two sensors were synchronized and recoded according to body position (lying, sitting, and upright).

State durations were calculated by accumulating time intervals for lying, sitting, and upright and state transitions between these positions per 24-h measurement. Time upright was calculated by merging time standing and time walking. A validation procedure was performed to control for possible time drifting of the sensors.

\section{Statistical analysis}

Demographic data were reported as mean values and standard deviation (SD) for all patients, and for three subgroups categorized by time from onset of symptoms to inclusion. Baseline characteristics were compared for those included within the first two days after stroke, those included 3 to 4 days after stroke and those included 5 to 7 days after stroke. This was done using a one-way ANOVA or Kruskal-Wallis test, depending on normality of residuals, which was judged by visual inspection of Q-Q plots. To assess changes in activity levels, we used linear mixed models (LMM) with time sitting, time upright, duration of sitting bouts and duration of upright bouts, respectively, as dependent variables, patients as random factor, and days since stroke as covariate. Next, we included the following covariates, one at a time: NIHSS, age, gender, mRS pre-stroke, mRS one day post stroke, and SPPB. Because the time spent lying, sitting and upright totaled $24 \mathrm{~h}$, only time spent sitting and upright were used in the mixed model analysis. Two-sided $p$-values less than 0.05 were considered statistically significant, and 95\% confidence intervals (CI) are reported where relevant. Statistical analyses were done in SPSS 23.

\section{Results}

The flow of patients is shown in Fig. 1. Of the 105 patients who met the inclusion criteria, 47 were excluded, mainly because of early discharge.

Fifty-eight patients (31 female) were included in the analysis. Patient characteristics are presented in Table 1. Mean (SD) time from onset of symptoms to inclusion was 2.6 (1.7) days, and patients wore the activity monitors for 5.8 (1.5) days. The NIHSS score was $6.2(5.0)$ points. Those included 4-7 days after symptom onset showed significantly lower scores on NIHSS as compared to those included within the first $24 \mathrm{~h}(p=0.002)$.

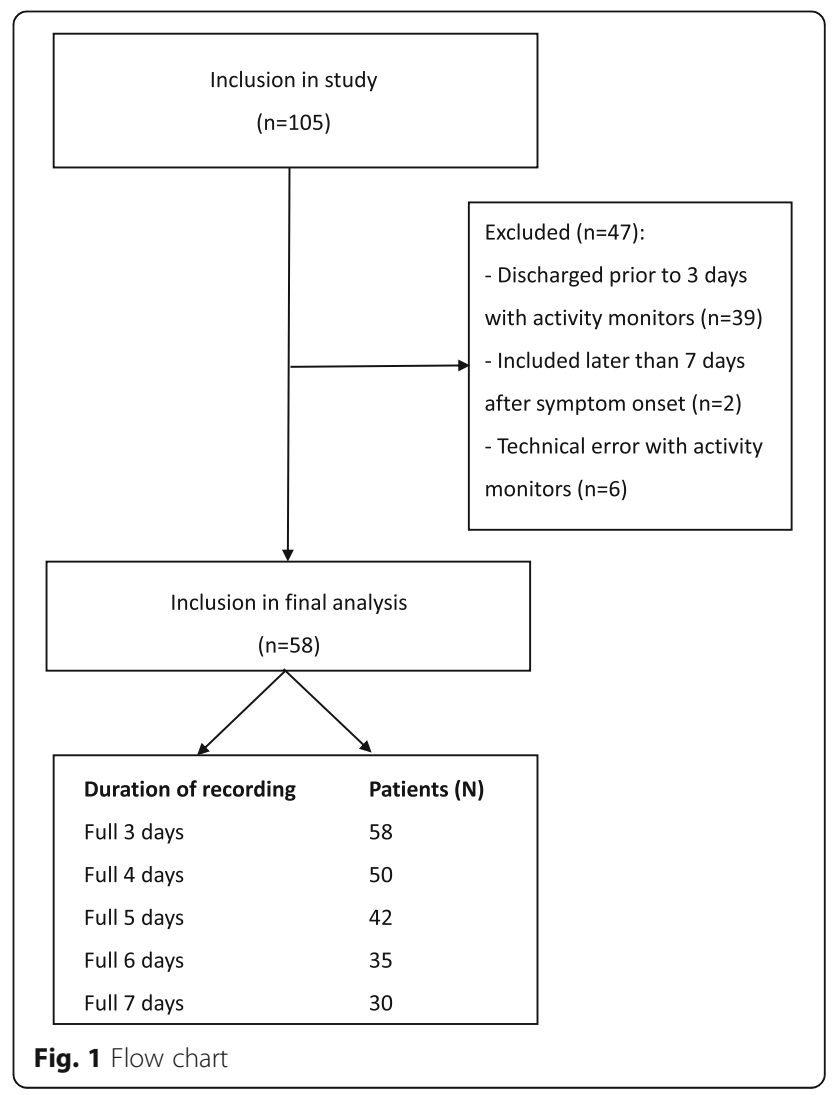


Table 1 Demographic data for included patients $(N=58)$

\begin{tabular}{|c|c|c|c|c|}
\hline & $\begin{array}{l}\text { Included } 0-2 \text { days from } \\
\text { symptoms }(n=19)\end{array}$ & $\begin{array}{l}\text { Included 3-4 days from } \\
\text { symptoms }(n=24)\end{array}$ & $\begin{array}{l}\text { Included 5-7 days from } \\
\text { symptoms }(n=15)\end{array}$ & Total $(n=58)$ \\
\hline Female gender, $n(\%)$ & $11(57.9)$ & $11(45.8)$ & $9(60.0)$ & $31(53.5)$ \\
\hline Age (years) & $72.9(10.0)$ & $76.6(13.1)$ & $75.3(12.1)$ & $75.1(12.0)$ \\
\hline Monitoring days & $5.8(1.6)$ & $5.8(1.6)$ & $6.0(1.3)$ & $5.8(1.5)$ \\
\hline Days hospitalized & $10.6(4.6)$ & $10.0(4.6)$ & $12.6(5.5)$ & $12.1(7.6)$ \\
\hline Days from stroke to inclusion & $0.9(0.3)$ & $2.4(0.5)$ & $5.0(1.3)$ & $2.6(1.7)$ \\
\hline NIHSS when admitted & $8.4(4.4)$ & $8.4(4.4)$ & $4.6(6.8)$ & $6.2(5.0)$ \\
\hline Median (IQR) & $7.0(6.0-13.0)$ & $4.0(3.0-7.0)$ & $3.0(2.0-5.0)$ & $5.0(3.0-8.0)$ \\
\hline \multicolumn{5}{|l|}{ Stroke severity groups, $n(\%)$} \\
\hline Mild (NIHSS < 8) & $13(68.4)$ & $19(79.2)$ & $14(93.3)$ & $46(79.1)$ \\
\hline Moderate (NIHSS 8-16) & $6(31.6)$ & $5(20.8)$ & $0(0.0)$ & $11(19.0)$ \\
\hline Severe (NIHSS > 16) & $0(0.0)$ & $0(0.0)$ & $1(6.7)$ & $1(1.7)$ \\
\hline mRS prior to stroke & $1.6(1.1)$ & $1.6(1.1)$ & $1.2(0.9)$ & $1.7(1.2)$ \\
\hline Median (IQR) & $1.0(1.0-2.0)$ & $2.0(2.0-3.0)$ & $1.0(1.0-2.0)$ & $2.0(1.0-2.3)$ \\
\hline mRS when admitted & $4.1(0.5)$ & $4.1(0.5)$ & $4.1(0.7)$ & $4.1(0.7)$ \\
\hline Median (IQR) & $4.0(4.0-4.0)$ & $4.0(4.0-5.0)$ & $4.0(4.0-4.0)$ & $4.0(4.0-4.3)$ \\
\hline Gait speed $(\mathrm{m} / \mathrm{s})$ & $1.7(1.6)$ & $1.5(0.9)$ & $1.2(1.2)$ & $1.5(1.2)$ \\
\hline SPPB & $5.1(3.8)$ & $5.1(3.8)$ & $3.9(3.5)$ & $4.4(3.5)$ \\
\hline Median (IQR) & $5.0(1.0-7.0)$ & $3.5(2.0-7.0)$ & $4.0(0.0-7.0)$ & $4.0(1.0-7.0)$ \\
\hline
\end{tabular}

Mean (SD) unless otherwise stated

NIHSS National Institute of Health Stroke Scale, mRS modified Rankin Scale, SPPB Short Physical Performance Battery

No other significant differences were found for the baseline variables.

Figure 2 illustrates the combinations of activities for each day, showing an increase in time spent out of bed during the hospital stay. Time spent upright remained low throughout the observation period.

Results from the LMM analysis (Table 2) show a daily increase in time spent sitting of $22.10 \mathrm{~min}(p<0.001)$ and 3.75 min upright $(p<0.001)$. Adjusted for time, we found that decreasing time spent upright was associated with increasing dependency, measured by mRS the first day after stroke $(p=0.002)$. An association was also found between time spent upright and physical function showing an increase of $6.97 \mathrm{~min}$ upright for every point increase on SPPB $(p=0.007)$. Neither severity of stroke nor age significantly influenced changes in overall physical activity.

Although not significant, LMM analysis indicated a daily increased duration of $4.32 \mathrm{~min}$ for each sitting bout $(p=0.051)$. Adjusted for time, this increase in time was associated with both a higher NIHSS score $(p=0.018)$ and increasing age $(p=0.028)$.

\section{Discussion}

In this study, we found that stroke patients increased their time spent sitting and upright during the initial hospital stay, with a corresponding decrease in time spent in a lying position. The duration of sitting bouts also increased over time, while the duration of upright bouts remained constant. Furthermore, overall increased time spent upright was associated with increasing independency (mRS) and improved physical function (SPPB), while prolonged sitting bouts were associated with higher age and more severe stroke.

Despite a statistically significant increase in time spent upright during the hospital stay, we may ask whether an estimated 3.75 min's more upright activity per day was a clinically significant change. This means that time spent

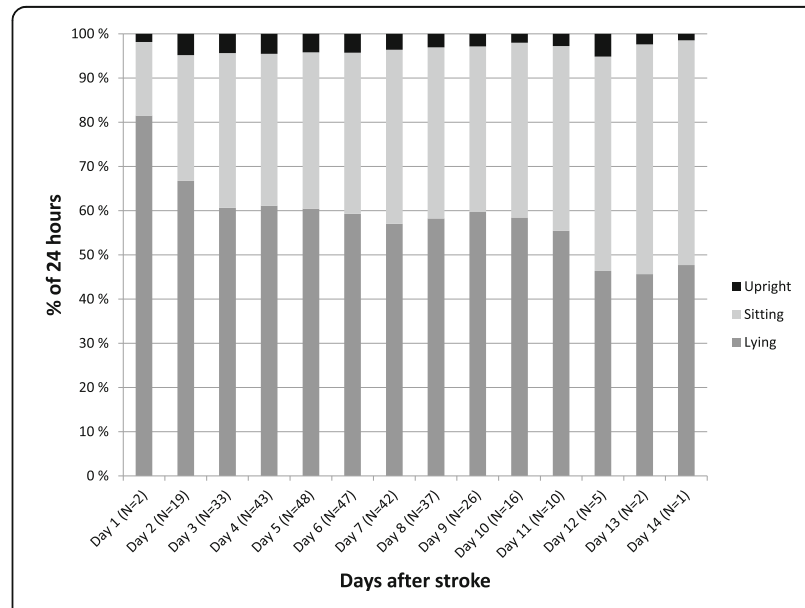

Fig. 2 Percentage of time spent in different positions within every $24 \mathrm{~h}$ 


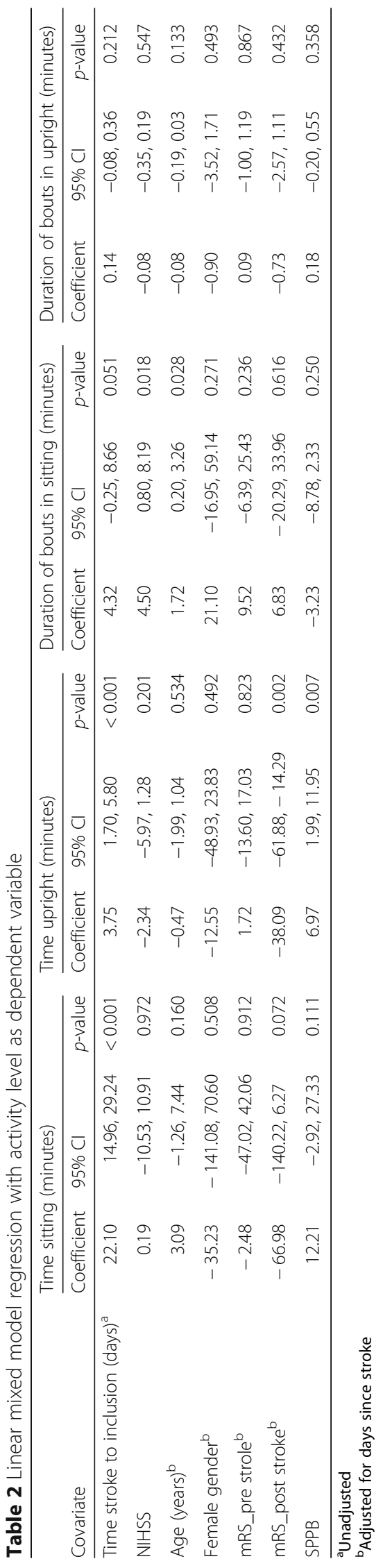


upright will increase by almost 40 min during a 10-day hospital stay. A previous study has shown that every 5 -min increase in time spent in bed was associated with a $4 \%$ deterioration on the mRS score three months later [6]. Hence, the daily increase in time spent upright could potentially have a great impact on functional recovery over time.

On the other hand, we found no association between stroke severity and time spent out of bed. This finding might be explained by the fact that activity measures during hospitalization also mirror the mobilization routines in the wards [33], showing that patients are mobilized out of bed as soon as they are medically approved, independent of the patients' ability to mobilize themselves.

The duration of each sitting bout also increased by more than 4 min per day during the hospital stay. More surprisingly, the increased duration of sitting bouts was associated with higher age and more severe stroke, while no associations were found for bouts in upright activity. These findings might be explained by the ability of less affected and younger patients to change position more often by themselves. This is interesting because it adds further knowledge to the ongoing debate regarding the intensity of early mobilization. Also, clinicians should be aware that patients with the most severe strokes who are not able to move independently are at increased risk of sedentary behavior, which might be harmful, thereby increasing the risk of poor outcome [6].

Our results show that stroke patients on average spend a significant proportion of each $24 \mathrm{~h}$ in a lying position (Fig. 2). Considering the 24-h monitoring, patients would normally spend at least $30 \%$ of the time sleeping. Still, patients spent almost $30 \%$ of the remaining time in bed. This corresponds with the high amount of time spent lying previously reported early after stroke $[14,17,25]$. One factor that could influence the low overall activity amongst our participants is the exclusion of those expected to be discharged within three days after inclusion, as these patients are likely to be more active. However, as we aimed to study change in physical activity over time, patients with short monitoring time had to be excluded.

The major strength of the present study was the prospective study design with continuous monitoring of activity, from two activity monitors, over $24 \mathrm{~h}$ for several days during the hospital stay. This allowed us to discriminate between lying, sitting and upright positions, which is of major importance in the acute phase after stroke. The use of such a protocol has been validated in the stroke population earlier, showing a high accuracy compared to video observation [26]. In contrast to observation of activity by, for example, behavioral mapping during daytime hours, usually for 9-10 h [7, 14, 17], continuous monitoring will account for out-of-bed time during $24 \mathrm{~h}$. It is also a strength that all included patients received evidence-based treatment in a comprehensive stroke unit combining acute medical treatment and early rehabilitation. Therefore, we know that our patients were mobilized according to recommendations in the national and international guidelines [27, 34], increasing the validity of the study.

A limitation of this study was the wide window for inclusion, ranging from one to seven days post stroke. This criterion was chosen for practical reasons, as recruitment was delayed during weekends and because the diagnosis was delayed in some patients (if the MR images were inconclusive or if patients were not admitted to hospital immediately after the first stroke symptoms). Nevertheless, apart from a significant difference in NIHSS between early and late admission to hospital, indicating that patients with the most severe symptoms are admitted to hospital earlier, we found no significant differences in the demographic data at baseline. However, the variation in time from onset of stroke to inclusion is accounted for in the LMM analysis. Our prolonged recruitment period (2013-2016), with three different time periods may also have influenced our results. The same routines were, however, applied for all stroke patients in the acute stroke treatment in the time periods. Therefore, all included patients, regardless of when they were recruited, should have received treatment focused on early rehabilitation. Another limitation is the lack of possibility to draw a causal relationship between the clinical parameters and the activity categories. Our secondary analysis indicate that the clinical parameters were influencing the activity levels. However, it is also possible to reverse this relationship, and to argue that the activity levels might influence the clinical parameters. Hence, it is important to have this possible bilateral relationship in mind when interpreting the results. Finally, the accelerometers used in this project do not discriminate between active and passive mobilization, and based on our inclusion criteria, mobilization may have been conducted with or without support from another person. This could influence both length and frequency of mobilization, as an active mobilization is naturally more tiring for the patient. However, in a comprehensive stroke unit, hospital staff are trained to activate stroke patients as soon as medically accepted, to encourage active rehabilitation. This means that even though some patients receive more support than others, all patients should be challenged according to their functional level.

\section{Clinical implications}

Our study supports previous findings showing that stroke patients spend most of their time in a lying or sitting position $[7,17,25,28]$, during hospitalization. The association between increased time spent upright and improved function indicates a need to pay specific 
attention to patients who depend on support to be able to transfer to an upright position to ensure frequent and short periods in upright activity throughout their hospital stay as recommended [21]. As older and more severely affected stroke patients may not be able to change position as often as independent patients, hospital staff also should pay extra attention to these patients when mobilizing them to a sitting position, to reduce sedentary time and avoid complications.

\section{Conclusion}

This study showed that time spent in sitting and upright positions increased throughout the hospital stay in patients admitted to hospital following a stroke. We found that these changes were associated with improved physical function and a higher degree of independence. There was also an increased duration of bouts spent sitting during hospitalization, with longer bouts associated with increasing age and more severe strokes. Future research should focus on defining the optimal dose of activity in the acute phase in order to improve function in the long term after stroke.

\section{Abbreviations}

Cl: Confidence Interval; IQR: Inter Quartile Range; LMM: Linear Mixed Model; MRS: Modified Rankin Scale; NIHSS: National Institute of Health Stroke Scale; SD: Standard Deviation; SPPB: Short Physical Performance Battery

\section{Acknowledgements}

We would like to thank the Department of Stroke for collaboration throughout the project. We would also thank the ongoing Norwegian Cognitive impairment after stroke (Nor-COAST) study for helpful collaboration in recruiting patients. Finally, we would like to thank patients and their families who agreed to participate in our study.

\section{Funding}

OPN was funded during the data collection by the Liaison Committee between the Central Norway Regional Health Authority and the University colleges.

\section{Availability of data and materials}

Due to Norwegian regulations and conditions for informed consent, the dataset is not publicly available.

\section{Authors' contributions}

AH and TA planned the study. AH and OPN recruited, and AH and OPN tested patients. BI was medically responsible for the included patients. OPN, $\mathrm{KT}$, and XT planned and processed data. OPN, SL, and TA performed the statistics by analyzing the data. OPN and TA interpreted the results. The manuscript was written by OPN and TA. All authors critically reviewed and approved the manuscript before it was submitted.

\footnotetext{
Authors' information

OPN (MSc) works as a physiotherapist at Clinical Services, Trondheim University Hospital and as a PhD student at the Norwegian University of Science and Technology (NTNU) in the Geriatric, Movement and Stroke (GeMS) group, Department of Neuromedicine and Movement Science, Faculty of Medicine and health science. AH (PhD) works as a medical doctor at The Norwegian Heart and Lung Patient Organization (LHL), Trondheim, Norway and as a researcher at Department of Neuromedicine and Movement Science, Faculty of Medicine and health science, NTNU. KT is a postdoctoral fellow with GeMS, Department of Neuromedicine and Movement Science, Faculty of Medicine and health science. XT works as a senior engineer with GeMS, Department of Neuromedicine and Movement
}

Science, Faculty of Medicine and health science. SL is a professor in medical statistics at Regional Centre for Child and Youth Mental Health and Child Welfare, Department of Mental Health, Faculty of Medicine and health science, NTNU. BI is head of the Stroke Unit at St. Olavs University Hospital and Adjunct Professor at the Department of Neuromedicine and Movement Science, Faculty of Medicine and health science, NTNU. TA is a professor at the Department of Neuromedicine and Movement Science, Faculty of Medicine and health science, NTNU.

\section{Ethics approval and consent to participate}

The study was approved by the Central Regional Committee for Medical and Health Research Ethics (REK no. 2013/1357) and approved by a member of the local stroke patient organization (Landsforeningen for slagrammede). Informed consent was obtained from those able to agree. For those not being able to provide informed consent, their next of kin was contacted and asked if they opposed participation. The decision of whether or not a participant was able to provide informed consent was made by the senior physician. This procedure is in keeping with Norwegian consent procedures for patients unable to consent, and was approved by the Ethics Committee.

\section{Consent for publication}

Not applicable.

Competing interests

The authors declare that they have no competing interests.

\section{Publisher's Note}

Springer Nature remains neutral with regard to jurisdictional claims in published maps and institutional affiliations.

\section{Author details}

${ }^{1}$ Department of Neuromedicine and Movement Science, Faculty of Medicine and health science, NTNU - Norwegian University of Science and Technology, Trondheim, Norway. ${ }^{2}$ Clinical Services, Department of Physiotherapy, St Olavs Hospital, Trondheim University Hospital, NO-7006 Trondheim, Norway. ${ }^{3}$ Clinic of Medicine, Department of Stroke, St. Olavs Hospital, Trondheim University Hospital, Trondheim, Norway. ${ }^{4}$ Regional Centre for Child and Youth Mental Health and Child Care, Department of Mental Health, Faculty of Medicine, NTNU - Norwegian University of Science and Technology, Trondheim, Norway.

Received: 5 March 2018 Accepted: 20 August 2018

Published online: 04 September 2018

\section{References}

1. Langhorne P, Pollock A. What are the components of effective stroke unit care? Age Ageing. 2002;31:365-71.

2. Organised inpatient (stroke unit) care for stroke. The Cochrane database of systematic reviews. 2013:Cd000197. doi: https://doi.org/10.1002/14651858. CD000197.pub3.

3. Indredavik B, Bakke F, Slørdahl S, Rokseth R, Håheim L. Treatment in a combined acute and rehabilitation stroke unit which aspects are most important? Stroke. 1999;30:917-23.

4. Ingeman A, Andersen G, Hundborg HH, Svendsen ML, Johnsen SP. Processes of care and medical complications in patients with stroke. Stroke. 2011;42:167-72. https://doi.org/10.1161/STROKEAHA.110.599738.

5. Chippala P, Sharma R. Effect of very early mobilisation on functional status in patients with acute stroke: a single-blind, randomized controlled trail. Clin Rehabil. 2016;30:669-75. https://doi.org/10.1177/0269215515596054.

6. Askim T, Bernhardt J, Salvesen O, Indredavik B. Physical activity early after stroke and its association to functional outcome 3 months later. J Stroke Cerebrovasc Dis. 2014;23:e305-12. https://doi.org/10.1016/j. istrokecerebrovasdis.2013.12.011.

7. Hokstad A, Indredavik B, Bernhardt J, Langhammer B, Gunnes M, Lundemo $C$, et al. Upright activity within the first week after stroke is associated with better functional outcome and health-related quality of life: a Norwegian multi-site study. J Rehabil Med. 2016;48:280-6. https://doi.org/10.2340/ 16501977-2051.

8. Yagi M, Yasunaga H, Matsui H, Morita K, Fushimi K, Fujimoto M, et al. Impact of rehabilitation on outcomes in patients with ischemic stroke: a 
Nationwide retrospective cohort study in Japan. Stroke. 2017:48:740-6. https://doi.org/10.1161/STROKEAHA.116.015147.

9. English C, McLennan H, Thoirs K, Coates A, Reviews BJ. Loss of skeletal muscle mass after stroke: a systematic review. Int J Stroke. 2010;5:395-402. https://doi.org/10.1111/j.1747-4949.2010.00467.x.

10. Herisson F, Godard S, Volteau C, Le Blanc E, Guillon B, Gaudron M. Early sitting in ischemic stroke patients (SEVEL): a randomized controlled trial. PLoS One. 2016;11:e0149466. https://doi.org/10.1371/journal.pone.0149466.

11. Murphy $\mathrm{TH}$, Corbett D. Plasticity during stroke recovery: from synapse to behaviour. Nat Rev Neurosci. 2009;10:861-72. https://doi.org/10.1038/ nrn2735.

12. Sundseth A, Thommessen B, Ronning OM. Outcome after mobilization within 24 hours of acute stroke: a randomized controlled trial. Stroke. 2012; 43:2389-94. https://doi.org/10.1161/STROKEAHA.111.646687.

13. Cumming TB, Thrift AG, Collier JM, Churilov L, Dewey HM, Donnan GA, et al. Very early mobilization after stroke fast-tracks return to walking: further results from the phase II AVERT randomized controlled trial. Stroke. 2011;42: 153-8. https://doi.org/10.1161/STROKEAHA.110.594598.

14. Bernhardt J, Chitravas N, Meslo IL, Thrift AG, Indredavik B. Not all stroke units are the same: a comparison of physical activity patterns in Melbourne, Australia, and Trondheim, Norway. Stroke. 2008;39:2059-65. https://doi.org/ 10.1161/STROKEAHA.107.507160.

15. Wellwood I, Langhorne P, McKevitt C, Bernhardt J, Rudd A, Wolfe C. An observational study of acute stroke care in four countries: the European registers of stroke study. Cerebrovasc Dis. 2009;28:171-6. https://doi.org/10. $1159 / 000226116$

16. Hokstad A, Indredavik B, Bernhardt J, Ihle-Hansen H, Salvesen O, Seljeseth YM, et al. Hospital differences in motor activity early after stroke: a comparison of 11 Norwegian stroke units. J Stroke Cerebrovasc Dis. 2015;24: 1333-40. https://doi.org/10.1016/j.jstrokecerebrovasdis.2015.02.009.

17. Askim T, Bernhardt J, Loge AD, Indredavik B. Stroke patients do not need to be inactive in the first two-weeks after stroke: results from a stroke unit focused on early rehabilitation. Int J Stroke. 2012;7:25-31. https://doi.org/10. 1111/j.1747-4949.2011.00697.x.

18. Bernhardt J, Dewey H, Thrift A, Donnan G. Inactive and alone: physical activity within the first 14 days of acute stroke unit care. Stroke. 2004;35:1005-9.

19. Bernhardt J, Langhorne P, Lindley RI, Thrift AG, Ellery F, Collier J, et al. Efficacy and safety of very early mobilisation within $24 \mathrm{~h}$ of stroke onset (AVERT): a randomised controlled trial. Lancet (London, England). 2015;386: 46-55. https://doi.org/10.1016/S0140-6736(15)60690-0.

20. Lynch E, Hillier S, Cadilhac D. When should physical rehabilitation commence after stroke: a systematic review. Int J Stroke. 2014;9:468-78. https://doi.org/10.1111/ijs.12262.

21. Bernhardt J, Churilov L, Ellery F, Collier J, Chamberlain J, Langhorne P, et al. Prespecified dose-response analysis for a very early rehabilitation trial (AVERT). Neurology. 2016;86:2138-45. https://doi.org/10.1212/WNL. 0000000000002459.

22. Davis MG, Fox KR. Physical activity patterns assessed by accelerometry in older people. Eur J Appl Physiol. 2007;100:581-9.

23. Mattlage AE, Redlin SA, Rippee MA, Abraham MG, Rymer MM, Billinger SA. Use of accelerometers to examine sedentary time on an acute stroke unit. J Neurol Phys Ther. 2015;39:166-71. https://doi.org/10.1097/NPT. 0000000000000092.

24. Baldwin C, van Kessel G, Phillips A, Johnston K. Accelerometry shows inpatients with acute medical or surgical conditions spend little time upright and are highly sedentary: systematic review. Phys Ther. 2017;97: 1044-65. https://doi.org/10.1093/ptj/pzx076.

25. Strømmen AM, Christensen T, Jensen K. Quantitative measurement of physical activity in acute ischemic stroke and transient ischemic attack Stroke. 2014;45:3649-55. https://doi.org/10.1161/STROKEAHA.114.006496.

26. Taraldsen K, Askim T, Sletvold O, Einarsen EK, Bjastad KG, Indredavik B, et al. Evaluation of a body-worn sensor system to measure physical activity in older people with impaired function. Phys Ther. 2011;91:277-85. https://doi. org/10.2522/ptj.20100159.

27. Helsedirektoratet. Nasjonal faglig retningslinje for behandling og rehabilitering ved hjerneslag. 2010.

28. Kramer SF, Cumming T, Churilov L, Bernhardt J. Measuring activity levels at an acute stroke ward: comparing observations to a device. Biomed Res Int 2013:2013:460482. https://doi.org/10.1155/2013/460482.

29. Gebruers N, Vanroy C, Truijen S, Engelborghs S, De Deyn PP. Monitoring of physical activity after stroke: a systematic review of accelerometry-based measures. Arch Phys Med Rehabil. 2010;91:288-97. https://doi.org/10.1016/j. apmr.2009.10.025.

30. Mijnarends DM, Meijers JM, Halfens RJ, ter Borg S, Luiking YC, Verlaan S, et al. Validity and reliability of tools to measure muscle mass, strength, and physical performance in community-dwelling older people: a systematic review. J Am Med Dir Assoc. 2013;14:170-8. https://doi.org/10.1016/j.jamda. 2012.10.009.

31. van Swieten JC, Koudstaal PJ, Visser MC, Schouten HJ, van Gijn J. Interobserver agreement for the assessment of handicap in stroke patients. Stroke. 1988;19:604-7.

32. Kasner SE, Chalela JA, Luciano JM, Cucchiara BL, Raps EC, McGarvey ML, et al. Reliability and validity of estimating the NIH stroke scale score from medical records. Stroke. 1999;30:1534-7.

33. Taraldsen K, Sletvold O, Thingstad P, Saltvedt I, Granat MH, Lydersen S, et al. Physical behavior and function early after hip fracture surgery in patients receiving comprehensive geriatric care or orthopedic care--a randomized controlled trial. J Gerontol A Biol Sci Med Sci. 2014;69:338-45. https://doi. org/10.1093/gerona/glt097.

34. Lord S, Galna B, Verghese J, Coleman S, Burn D, Rochester L. Independent domains of gait in older adults and associated motor and nonmotor attributes: validation of a factor analysis approach. J Gerontol A Biol Sci Med Sci. 2013;68:820-7. https://doi.org/10.1093/gerona/gls255.

\section{Ready to submit your research? Choose BMC and benefit from:}

- fast, convenient online submission

- thorough peer review by experienced researchers in your field

- rapid publication on acceptance

- support for research data, including large and complex data types

- gold Open Access which fosters wider collaboration and increased citations

- maximum visibility for your research: over $100 \mathrm{M}$ website views per year

At BMC, research is always in progress.

Learn more biomedcentral.com/submissions 